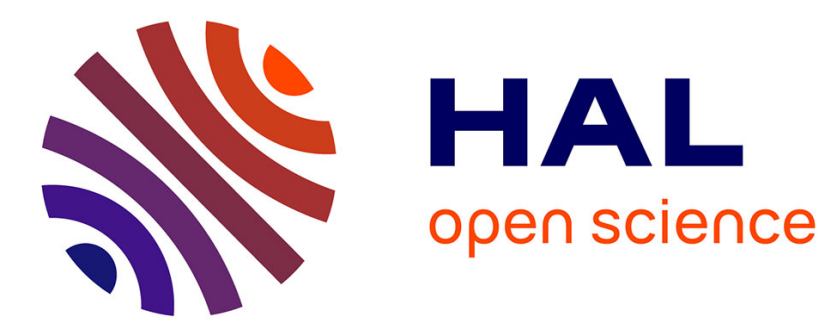

\title{
Distortions in Large Aluminum Forgings: Current Situation and Simulation Challenges
}

Ramiro Mena, Stéphane Guinard, Jose Aguado, Antonio Huerta

\section{To cite this version:}

Ramiro Mena, Stéphane Guinard, Jose Aguado, Antonio Huerta. Distortions in Large Aluminum Forgings: Current Situation and Simulation Challenges. Computation and Big Data for Transport, In press. hal-02454596

\author{
HAL Id: hal-02454596 \\ https://hal.science/hal-02454596
}

Submitted on 24 Jan 2020

HAL is a multi-disciplinary open access archive for the deposit and dissemination of scientific research documents, whether they are published or not. The documents may come from teaching and research institutions in France or abroad, or from public or private research centers.
L'archive ouverte pluridisciplinaire HAL, est destinée au dépôt et à la diffusion de documents scientifiques de niveau recherche, publiés ou non, émanant des établissements d'enseignement et de recherche français ou étrangers, des laboratoires publics ou privés. 


\title{
Distortions in Large Aluminum Forgings: Current Situation and Simulation Challenges
}

\author{
Ramiro Mena ${ }^{1,2,3, a)}$, Stéphane Guinard ${ }^{1}$, José V. Aguado ${ }^{2}$, and Antonio \\ Huerta $^{3}$ \\ ${ }^{1}$ Airbus SAS, France \\ ${ }^{2}$ Institut de Calcul Intensif ICI-HPC at École Centrale de Nantes, France \\ ${ }^{3}$ Laboratori de Calcul Numeric (LaCaN). Departament de Matematica Aplicada III. \\ E.T.S. de Ingenieros de Caminos, Canales y Puertos, Universitat Politecnica de \\ Catalunya, Spain \\ ${ }^{a)}$ Corresponding author: ramiro-francisco.mena-andrade@airbus.com
}

\begin{abstract}
Distortions after machining of large aluminum forgings are a recurrent problem for the aeronautical industry. These deviations from design geometry are caused by the presence of residual stresses, which are developed along the manufacturing chain. To solve this problem, a series of post-machining operations called reshaping are required. Despite reshaping manages to restore the correct geometry, it is highly manual and time-consuming, therefore, there is a need at an industrial level to use numerical simulation to study reshaping. The present document describes the problem of distortion, the operations required to mitigate these geometrical defects and the challenges associated to simulate reshaping.
\end{abstract}

Keywords: Distortions, Residual Stresses, Reshaping, Simulation

\section{Introduction}

Large and thick-walled aluminum forgings are widely used in the aeronautical industry. The key material properties as a great strength-to-weight ratio and good formability in combination with the manufacturing process allow producing complex shapes in an economical way [14]. Additionally, when compared to other metal working processes (e.g extensive machining, welding or casting), improved material properties as grain size and orientation are obtained [19]. However, aluminum forgings show important distortions after machining due to the presence of residual stresses which are a consequence of the non-homogeneous plastic strains developed along the manufacturing chain, especially after the heat treatment of quenching $[15,22]$.

Such distortions are variable in nature, but the industrial process incorporates a robust post-machining stage called reshaping. Particularly, skilled boilermakers operate a sequence of mechanical loadings on the non-conforming part and re-establish its nominal geometry while obeying guidelines imposed by stress offices - which guarantees the produced part has still mechanical characteristics 
compatible with its operational role -. An example of the structural parts subjected to reshaping are the cruciform beams, located at the wing-box in an aircraft and highlighted in red in Figure 1. On the other hand, reshaping is a highly manual and collaborative process as multiple operators are involved to repair one single part. At the same time, the process fully depends on the experience of the boilermakers and repairing each structural part in a tailor-made manner is time-consuming. Therefore, there is a strong demand from the industry to derive operational assistance from capabilities offered by numerical simulation tools [25].

Focus on distortion mitigation via reshaping, numerical simulations may offer huge margins for improvements such as operational assistance to boilermakers and related gains in time-cycle (optimized reshaping sequence, optimized parameters for each elementary reshaping operation), improved knowledge of actual part and related gains in safety (monitoring of actual plastic strains). However, some research efforts are required in order to migrate from the actual heuristic repairing method to a simulation-assisted operation, as reshaping simulations present challenges to be solved as the elevated computational cost of each simulation or the use of static data of traditional Finite Element Analysis (FEA), to name a few.

This report describes the distortions on aluminum forgings, the operations required to solve this problem and the challenges associated with deploying numerical simulations at workshop level and actually help operators. The document is structured as follows: Section 2 provides an overview of distortions as an open problem for the aeronautical industry. Then, the relation between residual stresses, distortions, and reshaping are explained in Section 3. Next, the different reshaping operations are described in detail in Section 4 and the challenges and perspectives to simulate reshaping are reviewed in Section 5. Finally, the obtained conclusions are presented.

\section{Distortion in the aeronautical industry: an open problem}

To the best of our knowledge, the problem of distortions in the aeronautical industry was first reported during World War II, when some difficulties were experienced with extrusions used for aircraft spars parts [12]. Then, due to the technology transfer performed after the war, the use of large forgings for light metals alloys (i.e magnesium and aluminum) was potentiated with governmental initiatives as the Air Force Heavy Press Program in the United States, which allowed the construction of forgings up to $50 \mathrm{k}$ tons capacity ${ }^{1}$ [2]. Thanks to this new range of tools, the unitization ${ }^{2}$ of structural parts was feasible and acted as a driving force for the development of bigger aircraft with important manufacturing costs savings [3, 27]. On the other hand, as the forgings grew in size and

\footnotetext{
${ }^{1}$ Nowadays, the biggest forging has a capacity of $80 \mathrm{k}$ ton and is located in China [10].

${ }^{2}$ Action to replace composite structures to single components
} 


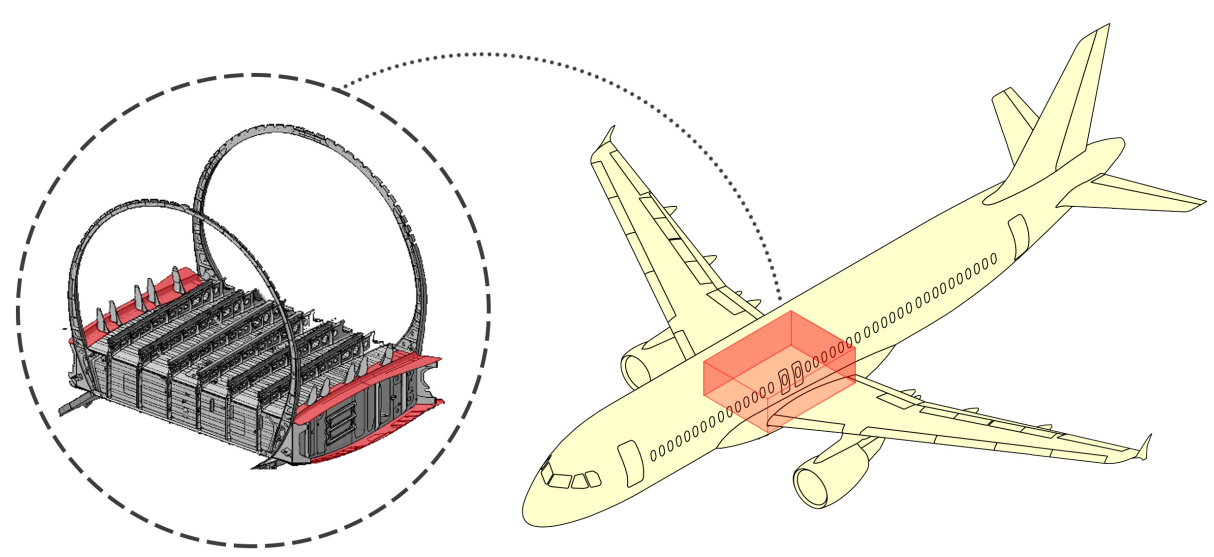

Fig. 1. Example of aluminum forgings subjected to distortion: cruciform of the A320 wingbox (depicted in red)

with them their cross sections and wall thickness, the range of residual stresses developed after quenching experienced an increment too, so as the research interest to predict the residual stresses and any future distortion after machining $[13,21]$.

At an industrial level, different attempts have been made to minimize distortion along the manufacturing chain of heat-treated aluminum alloys components. In North America, the MAI (Metals Affordability Initiative) program [3, 15] and in Europe, the COMPACT (A COncurrent approach to Manufacturing induced Part distortion in Aerospace ComponenTs) project [22, 25, 26], focused on the understanding of residual stress and part distortion. However, both initiatives efforts were concentrated on the upstream manufacturing processes, such as quenching, stress relief, ageing, and machining, letting reshaping unattended and as a byproduct. Theoretically, if distortion is controlled or minimized, then reshaping is unnecessary. Unfortunately, a part with minimized distortions is only achieved in exceptional cases [17]. Therefore, we can state that distortion is an open problem for the industry during the last 80 years.

\section{Residual Stresses, Distortion and Reshaping}

In the distortion mitigation problem, there are three main actors: residual stresses, distortion, and reshaping. They can be considered as the source, the problem, and the current solution, respectively. At the same time, they are interconnected and interact between them, as represented in Figure 2. In the following section, a definition for each actor is provided.

Residual stresses refer to any stress distribution, which is present in a solid in the absence of an external load or thermal gradient [23]. In a material, the residual stress distribution is a direct consequence of non-homogeneous plastic defor- 


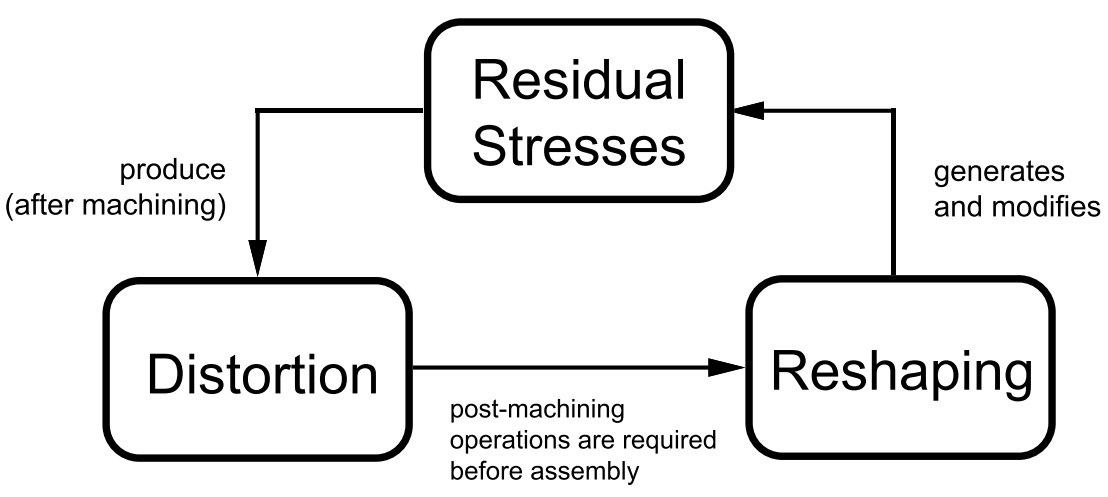

Fig. 2. Interaction between Residual Stresses, Distortion and Reshaping.

mations arising from transformations endured during the manufacturing process. Based on its characteristic length scale, residual stresses are classified as type I, II and III, corresponding to macro stresses, intergranular stresses, and stresses at an atomic scale, respectively [29]. For distortion generation/mitigation, only residual stresses of type I are considered as this scale includes the stresses along the cross-section. This type of stresses can be induced by thermal or mechanical loading (e.g. welding and/or ultrasonic shoot penning).

Sim [25] defines distortion after machining as the shape deviation respect to the design geometry once the part is released from the fixture clamps. This problem is not caused by machining tolerance, over/under machining or dimensional inaccuracy. In a general way, distortion can be classified into two categories: in-plane and out-of-plane. Nevertheless, more complex patterns are present in forgings parts. Marin [16] documented the principal types of distortions present on a cruciform as shown in Figure 3, where each type of distortion is represented in an isolated way. However, in a real part, all five types of distortions are combined simultaneously with the additional challenge that every time a new part is machined, a different magnitude of distortion is obtained.

Reshaping can be defined as the post-machining operations required to mitigate distortion. The general idea is to induce distortion on the contrary direction of the actual warped geometry to counteract the geometrical defect and restore the design geometry within a given tolerance. To perform this task, the material must be taken to the plastic regimen with the aim to induce plastic strains in the part. A detailed description of the reshaping operations is provided in the next section.

Now that the main actors are defined, it is easier to explain the whole picture of distortion. First, residual stresses appear after quenching. This heat treatment is the main source of residual stresses as the core of the part and its surface are subjected to different and strong thermal gradients. As a consequence, once the 

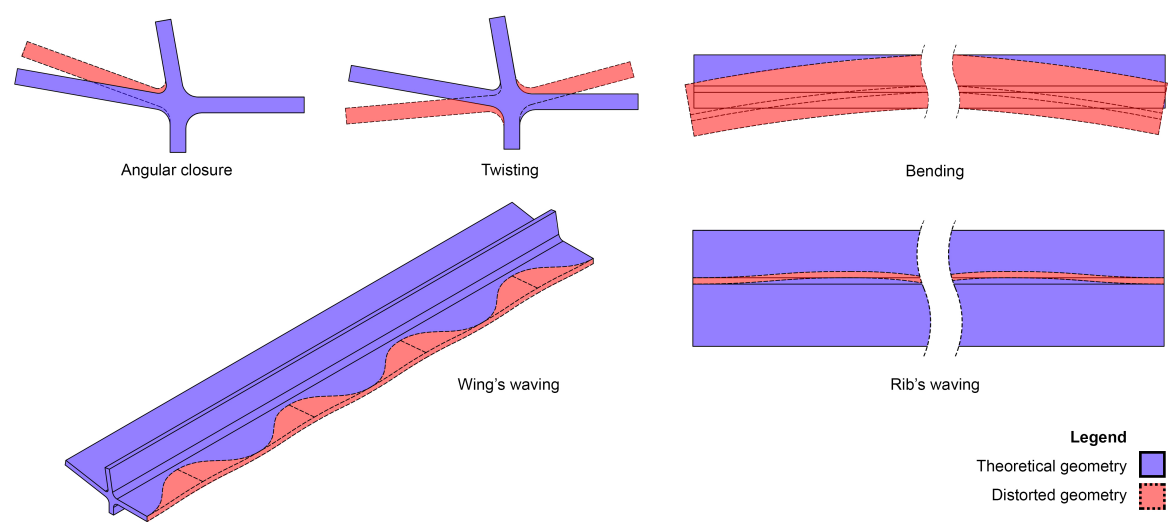

Fig. 3. Principal types of distortion present on an A320 cruciform after machining. Adapted from [16]

part reaches the room temperature, there is a bi-axial compression stress distribution at the surface which is counterbalanced by a three-dimensional tension state in the core [22]. However, its internal distribution evolves each time a new operation is performed in the manufacturing chain. After quenching, the part continues with a stress relief process, followed by a second heat treatment called ageing, both processes aiming at minimizing residual stresses before machining. Then, during machining, the material removal breaks the equilibrium state of the current residual stresses, producing a redistribution of residual stresses. As a consequence, distortion appears. Next, each time reshaping is applied, new residual stresses are introduced to the part until the theoretical geometry is restored within the design's tolerance.

\section{Post-machining distortion mitigation techniques}

Once distortions are present after machining, it is mandatory to remove the geometrical deviations before proceeding to the assembly stage. In that way, the installation of the structural part into the corresponding sub-component is easier and the addition of unexpected stresses into the system is avoided. To perform this task, there are four reshaping operations available: bending straightening, torsion straightening, roller burnishing, and ultrasonic needle peening, as shown in Figure 4.

Bending straightening is an elastic-plastic operation. Depending on the part's geometry and dimensions, it can be used to remove globally a longitudinal distortion or locally the wing's waving (see Figure 3). After unloading, the residual stresses along the cross-section present the so-called three zero-crossing distribution, as depicted in Figure 5a. From a material science point of view, bending straightening and its non-homogeneous deformation produces a rearrangement 

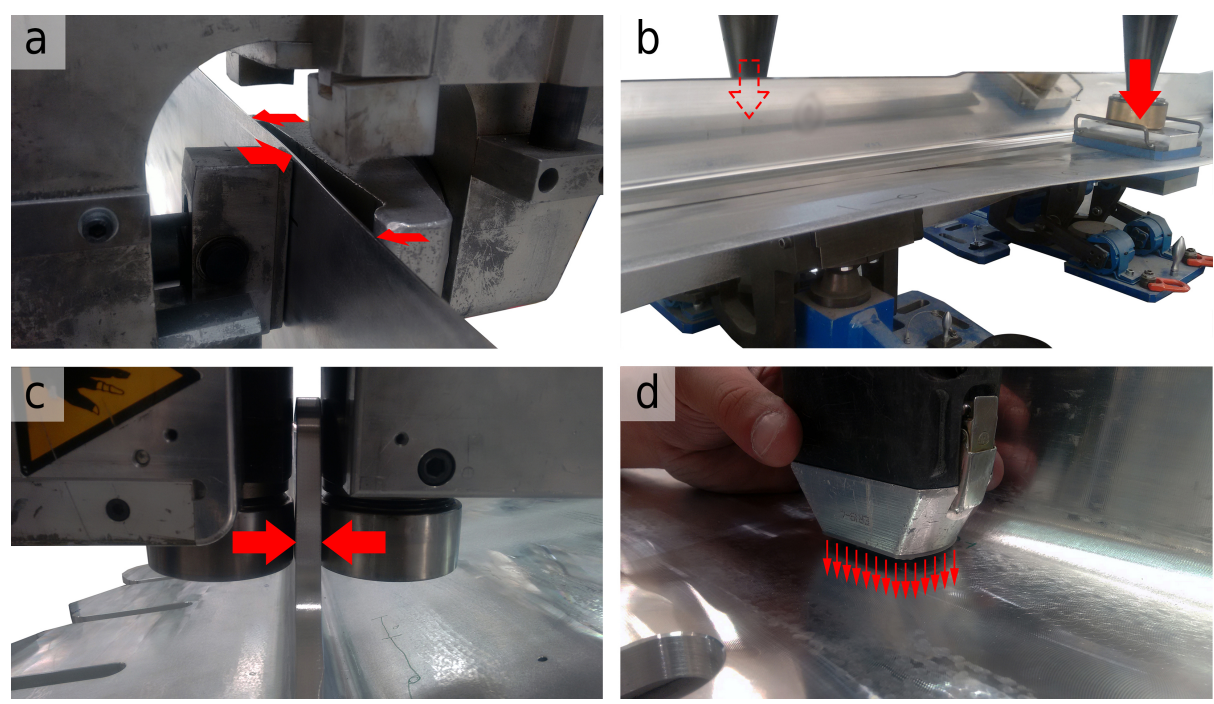

Fig. 4. Reshaping operations used at Airbus: (a) Bending, (b) Torsion, (c) Roller burnishing and (d) Ultrasonic needle peening.

of existing residual stresses [11], causes non-homogeneous material properties, anisotropy of strength and Bauschinger effect [24].

Similar to the previous process, torsion straightening is an elastic-plastic operation too. For simple cylindrical geometries, after unloading, the residual stresses present the so-called three zero-crossing distribution, as depicted on Figure $5 \mathrm{~b}$ but instead of the compression-tension stresses generated during bending, shear stresses are produced. For more complex geometries as rectangular or I sections, the membrane analogy can be used [28] and it is reported that the plastic range is obtained first at the round fillets for I beams $[8,20]$. This operation is used to correct any twisting distortion and as its bending counterpart, suffers from the presence of springback during unloading which has to be taken into account.

Roller burnishing is a surface finishing method that induces a plastic deformation under cold working conditions by applying pressure through a cylindrical tool [18]. In the context of reshaping, it is used to modify the distribution of residual stresses by inducing a local compressive residual stress at the surface and for our specific case, two rollers are used, as shown in Figure 4c. This configuration produces a symmetric residual stress distribution as depicted in Figure 5c. By applying this method, surface irregularities are removed. As a consequence, a smooth and shiny surface with better fatigue strength is obtained [1]. The depth of the work-hardening layer depends on the process parameters and material, but in general, it is small and varies between $0.2-1 \mathrm{~mm}[9,18]$.

Ultrasonic needle peening is a special case of shot peening. Here, instead of using the traditional spheres to hit the part and induce compressive residual 


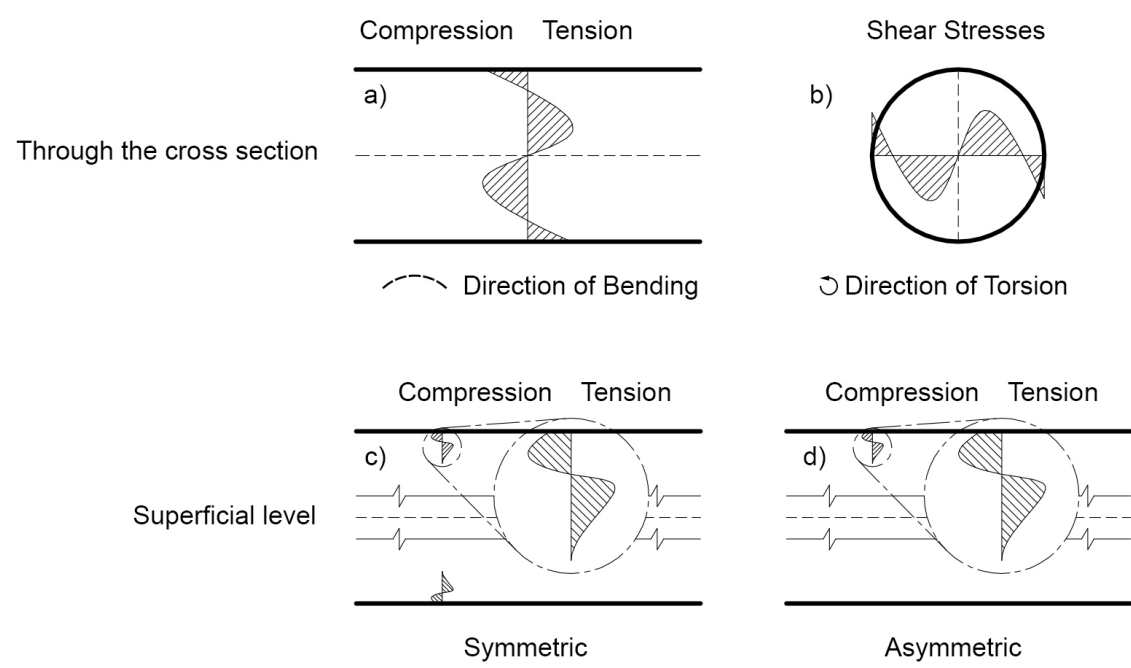

Fig. 5. Residual stress process signature after unloading: (a) Bending, (b) Torsion, (c) Roller burnishing and (d) Ultrasonic needle peening. Adapted from [1, 12]

stresses at the surface of the component, oscillating cylindrical bars in the ultrasonic range (over $18 \mathrm{kHz}$ ) are employed [30]. This operation stretches plastically the area where is applied and, in order to counterbalance this effect, it produces an S-shape residual stress profile starting with a compressive layer followed by a tension zone underneath, as represented in Figure 5d [23]. The method is characterized to be manual, fast and easy to apply, as the tool can be easily handled by the operator. On the other hand, the area of influence of the residual stresses is smaller respect to the cross-section and normally, it is applied to a single side of the part, giving as a result an asymmetric residual stress distribution.

The corrective stage of reshaping is an iterative operation and its work-flow diagram is represented in Figure 6. Starting from the initial geometry, a measurement and control step is performed in order to determine the level of distortion. Based on the result, one of the four reshaping operations described before is selected. To perform one single plastic deformation step, the selected reshaping operation needs to be configured, it means, the technological parameters $\mu_{i}$ (e.g position, imposed displacement, length of the application) need to be defined. This process is repeated until the part is repaired and fits into the design tolerance.

\section{Reshaping simulation: challenges and perspectives}

As stated before, nowadays, reshaping relies on the experience of a group of welltrained operators, the boilermakers. The goal to introduce numerical simulation 


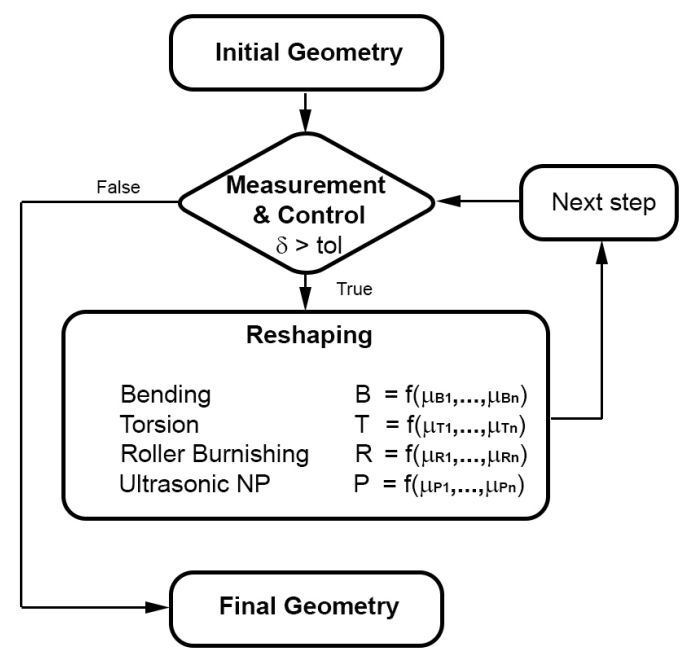

Fig. 6. Reshaping simulation workflow diagram

in this process is to assist the operators and provide support during the decisionmaking step in order to reduce the number of operations needed to repair a part. However, from a technical point of view, reshaping simulation presents the following challenges:

- the initial distortion after machining $\delta_{0}$ is unknown and, with the available state-of-the-art simulation techniques, there is a mismatch between the numerical prediction and the real distortion.

- distortions vary from one part to other (non-reproducibility), that is why reshaping cannot be standardized.

- simple 2D calculations are not able to represent properly neither the parts geometry nor the distortion phenomenon, and as a consequence, 3D simulations are required.

- each time a new reshaping operation is performed, distortion changes and with it, the next reshaping operation and its technological parameters.

- to implement the numerical assistance in an industrial context, a real-time response is required.

The first challenge is related to an accurate prediction of residual stresses along the manufacturing chain. Theoretically, if the residual stress in a forged part is known before the machining step, it would be possible to determine the best location for the final geometry inside the blank, which minimizes any possible distortion. This approach works well for parts made from rolled plates $[4,6]$ due to the residual stress field is easier to determine compared to forged parts [25]. For the latter, important deviations from the numerical prediction 


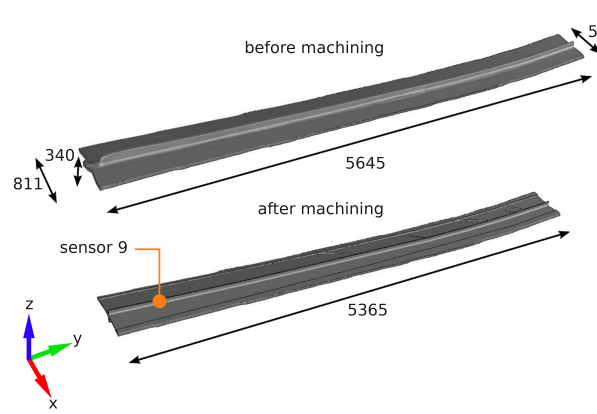

(a)

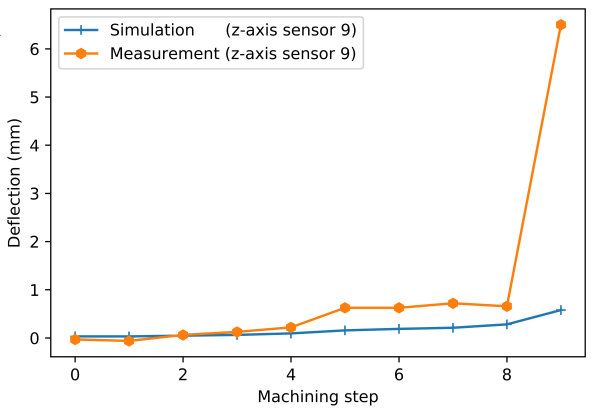

(b)

Fig. 7. Example of distortion in a cruciform. (a) Geometry before and after machining. (b) Simulation vs measurements results. Adapted from [5].

respect to the real distortion where reported by Cerutti [5], as shown in Figure 7. As a consequence, any mismatch between the numerical and real initial distortion can invalidate any further reshaping simulation step.

The second limitation is due to the deterministic nature of numerical simulations. Once the solution has converged, if the algorithm is executed again, it is expected to obtain the same result (e.g. $\left.\delta_{0}\right)$ while in reality, every time a new forged part is machined, although all the process parameters were not modified, a different value for $\delta_{0}$ is obtained. This pattern is observed between parts of the same class and among symmetric parts (e.g left and right cruciform). Therefore, reshaping simulation needs to provide multiple possible initial distortion scenarios.

The use of 3D simulations to represent properly the distorted geometry implies the generation of numerical models with large degrees of freedom. It is a common practice to take advantage of any symmetry plane in order to simulate only one portion of the total part. Maybe the symmetry trick can be exploited during the first reshaping step. However, as the problem evolves and distortion gets more localized, the way each reshaping operation is applied obliges to simulate the whole structure.

About the fourth challenge, for each reshaping step $i=1,2,3, \ldots$, the goal is to define the parameters associated with the operation $\mu_{i}$ that minimize the remaining distortion $\delta_{i}$. It means that, for each reshaping step, it is required to run a multi-parametric analysis. The problem's complexity grows as previous and subsequent operations influence each other. Therefore, any error generated during a defined reshaping step will be forward propagated and can invalidate the simulation results.

In order to implement this numerical assistance tool in an industrial environment, it is required to access the simulation outputs in real-time, as the goal is to evaluate beforehand different scenarios for the reshaping step $i$ and only then, to launch the real operation with the optimum configuration defined in advance. 
Under the described scenarios, the requirement of multiple reshaping simulations together with adaptive modeling and a real-time response suggests launching a multi-parametric analysis under a Model Order Reduction (MOR) framework. The idea for this approach is to produce a low-dimensional but accurate model in a cost-effective way which allows exploring beforehand the input space to construct a solution dictionary, known as computational vademecum [7].

\section{Conclusions}

Distortion of large aluminum forgings is an open problem for the aeronautical industry. Continuous research efforts are done in order to predict the residual stresses that generate this problem. However, it is important from an operational standpoint to study how to handle distortion once it has appeared. In this document, the required post-machining operations to mitigate distortion has been reviewed together with their associated challenges to simulate them. At the moment, reshaping is solved based on the empirical experience acquired for a group of well-trained operators. Now, the goal is to find a way to use advanced numerical simulations tools (e.g adaptive modeling, model order reduction) to study reshaping in a virtual environment and evaluate possible scenarios before launching the real operation. The long-term goal is to optimize the process in order to minimize the total number of reshaping operations and avoid introducing unnecessary residual stresses to the structural part.

Acknowledgements. This project is part of the Marie Skłodowska-Curie ITNETN AdMoRe funded by the European Union Horizon 2020 research and innovation program with grant number 675919 . 


\section{References}

[1] Akkurt, A.: Comparison of roller burnishing method with other hole surface finishing processes applied on aisi 304 austenitic stainless steel. Journal of Materials Engineering and Performance 20(6), 960-968 (2011)

[2] ASME: The Wyman-Gordon 50,000-Ton Forging Press. Tech. rep., The American Society of Mechanical Engineers (ASME) (1983)

[3] Ball, D., Dubowski, D., Spradlin, T.: Inclusion of Forging Residual Stresses in Large Component Structural Design. In: 2016 USAF Aircraft Structural Integrity Program Conference (2016)

[4] Cerutti, X., Mocellin, K., Hassini, S., Blaysat, B., Duc, E.: Methodology for aluminium part machining quality improvement considering mechanical properties and process conditions. CIRP Journal of Manufacturing Science and Technology 18, 18-38 (2016), http://dx.doi.org/10.1016/j.cirpj . 2016.07 .004

[5] Cerutti, X.: Numerical modelling and mechanical analysis of the machining of large aeronautical parts: Machining quality improvement. Ph.D. thesis, Ecole Nationale Supérieure des Mines de Paris (2014)

[6] Chantzis, D., Van-Der-Veen, S., Zettler, J., Sim, W.M.: An industrial workflow to minimise part distortion for machining of large monolithic components in aerospace industry. Procedia CIRP 8, 281-286 (2013), http://dx.doi.org/10.1016/j.procir.2013.06.103

[7] Chinesta, F., Leygue, A., Bordeu, F., Aguado, J.V., Cueto, E., Gonzalez, D., Alfaro, I., Ammar, A., Huerta, A.: PGD-Based Computational Vademecum for Efficient Design, Optimization and Control. Archives of Computational Methods in Engineering 20(1), 31-59 (2013)

[8] Christopherson, D.G.: A Theoretical Investigation of Plastic Torsion in an I-Beam. The Aeronautical Journal 44(353), 425-432 (1940)

[9] Coules, H.E., Horne, G.C., Kabra, S., Colegrove, P., Smith, D.J.: Threedimensional mapping of the residual stress field in a locally-rolled aluminium alloy specimen. Journal of Manufacturing Processes 26, 240-251 (2017), http://dx.doi.org/10.1016/j.jmapro.2017.02.010

[10] Du, J., Deng, Q., Dong, J., Xie, X., Wang, Z., Zhao, C., Chen, G., Xie, W., Luo, T., Wang, X., Zhang, Y.: Recent Progess of Manufacturing Technologies on C\&W Superalloys in China. In: Ott, E., Banik, A., Liu, X., Dempster, I., Heck, K., Andersson, J., Groh, J., Gabb, T., Helmink, R., Wusatowska-Sarnek, A. (eds.) 8th International Symposium on Superalloy 718 and Derivatives. pp. 33-46. TMS (The Minerals, Metals \& Materials Society) (2014)

[11] Ellermann, A., Scholtes, B.: Residual stress states as a result of bending and straightening processes of steels in different heat treatment conditions. International Journal of Materials Research 103(1), 57-65 (2012) 
[12] Forrest, G.: Internal or Residual Stresses in Wrought Aluminium Alloys and their Structural Significance. Journal of the Royal Aeronautical Society pp. 261-276 (1954)

[13] Jeanmart, P., Bouvaist, J.: Finite element calculation and measurement of thermal stresses in quenched plates of high-strength 7075 aluminium alloy. Materials Science and Technology 1(October), 765-769 (1985)

[14] Kalpakjian, S., Steven, S.: Manufacturing Processes for Engineering Materials. 7th edn. (2014)

[15] Ma, K., Goetz, R., Srivatsa, S.K.: Modeling of Residual Stress and Machining Distortion in Aerospace Components. In: Furrer, D., Semiatin, S. (eds.) Metals Process Simulation, pp. 386-407. ASM International (2010)

[16] Marin, G.: Calcul et optimisation des structures mécaniques. Ph.D. thesis, Université Technologique Compiègne (2000)

[17] Mitze, M.: Straightening heat-treated components. Journal of Heat Treatment and Materials 65, 110-117 (2010)

[18] Murthy, R.L., Kotiveerachari, B.: Burnishing of metallic surfaces - a review. Precision Engineering 3, 172-179 (1981)

[19] Narahari Prasad, S., Rambabu, P., Eswara Prasad, N.: Processing of Aerospace Metals and Alloys: Part 2 - Secondary Processing. In: Prasad, N., Eswara, Wanhill, R. (eds.) Aerospace Materials and Material Technologies, vol. 2, pp. 199-228. Springer Singapore (2017), https://link.springer. com/content/pdf/10.1007\%2F978-981-10-2134-3.pdf

[20] Pi, Y.L., Trahair, N.S.: Inelastic Torsion of Steel I-Beams. Journal of Structural Engineering 121(4), 609-620 (1995)

[21] Robinson, J.S., Tanner, D.A., Truman, C.E.: 50th anniversary article: The origin and management of residual stress in heat-treatable aluminium alloys. Strain 50(3), 185-207 (2014)

[22] Robinson, J., Hossain, S., Truman, C., Paradowska, A., Hughes, D., Wimpory, R., Fox, M.: Residual stress in 7449 aluminium alloy forgings. Materials Science and Engineering: A 527(10-11), 2603-2612 (2009)

[23] Schijve, J.: Residual Stress. In: Fatigue of Structures and Materials, pp. 89-104 (2009)

[24] Schott, C., Ellermann, A., Zinn, W., Scholtes, B.: Consequences of bend straightening processes on residual stresses and strength of quenched and tempered steels. HTM - Journal of Heat Treatment and Materials 71(2), $75-82(2016)$

[25] Sim, W.: Challenges of residual stress and part distortion in the civil airframe industry. In: 2nd International Conference on Distortion Engineering. pp. 87-94 (2008)

[26] Sim, W.: Residual Stress Engineering in Manufacture of Aerospace Structural Parts. 3rd International Conference on Distorsions Engineering pp. 187-194 (2011)

[27] Smith, C., Crowther, J.: The Production of Large Forgings in Aluminium Alloys. Journal of the Royal Aeronautical Society 59(537), 604-612 (1955)

[28] Timoshenko, S.: Strength of Materials: Part II Advanced Theory and Problems. D.Van Nostran Company, Inc., 2nd edn. (1940) 
[29] Withers, P., Bhadeshia, H.: Residual stress. Part 1 Measurement techniques. Materials Science and Technology 17(4), 355-365 (2010)

[30] Yin, F., Rakita, M., Hu, S., Han, Q.: Overview of ultrasonic shot peening. Surface Engineering 33(9), 651-666 (2017) 